\title{
Tooth Discoloration
}

National Cancer Institute

\section{Source}

National Cancer Institute. Tooth Discoloration. NCI Thesaurus. Code C80112.

A change in tooth color. Causes may be local or systemic and include tobacco use, foods, dental plaques, caries, restorative filling materials, trauma, medications, infections, hereditary diseases, and nutritional deficiencies. 